\title{
summary
}

\section{Downward trend in African caries levels?}

Cleaton-Jones P, Fatti P. Dental caries trends in Africa. Community Dent Oral Epidemiol 1999; 27:316-320

Objective To determine trends in published dental caries rates in Africa.

Data sources Medline search for period 1967-1997. Keywords used were 'dental caries' and names of African countries.

Study selection For inclusion an article had to have cleared defined ages within four groupings $(5-6 ; 11-13 ; 14-15 ; 35-44)$, used the WHO diagnostic criteria, the sample had to have been indigenous Africans and contain more than 30 individuals.

Results The search identified 327 articles; 69 were epidemiological studies, of which 45 fulfilled the inclusion criteria. Eleven separate African counties were represented.

\begin{tabular}{lcccc}
\hline & \multicolumn{2}{c}{ Percentage with caries } & \multicolumn{2}{c}{$\begin{array}{c}\text { Caries severity } \\
\text { (mean dmft/DMFT ) }\end{array}$} \\
\hline & $\begin{array}{c}\text { Number of } \\
\text { groups }\end{array}$ & Trend & $\begin{array}{c}\text { Number of } \\
\text { groups }\end{array}$ & Trend \\
\hline $11-13$ (rural) & 12 & Decreased & 15 & Decreased \\
$5-6$ (urban) & 24 & Decreased & 27 & Decreased* \\
$11-13$ (urban) & 22 & Decreased & 31 & Increased \\
$14-15$ (urban) & 12 & Increased & 13 & Increased \\
35-44 (urban) & 8 & Decreased & 8 & Decreased* \\
\hline
\end{tabular}

*Significant at $p<0.05$.

Conclusion The study showed a predominantly downward trend in dental caries, which was statistically significant for $\mathrm{dmft}$ at 5-6 years and DMFT at 35-44 years.

Address for reprints: Dental Research Institute, Private Bag 3, WITS, 2050, South Africa. E-mail: 0078cleat@chiron.wits.ac.za

\section{Commentary}

There are divergent views on whether dental caries is increasing or decreasing in Africa. This disagreement stems partly from the diversity of populations in Africa and the varying standards of the surveys done. Another factor is that, in countries such as South Africa, the trends in caries among white South Africans, who have access to fluoride toothpastes, differ from the poorer black population.

This systematic review attempts to resolve the question on trends by analysing data from a selection of the 69 epidemiological studies suitable for inclusion. After further assessment only 45 satisfied the inclusion criteria.

The conclusions of the study are not borne out by the results and there are some shortcomings in the analysis. First, the majority of 107 study groups included are from two countries: South Africa (32) and Tanzania (26). Second, most were from 1980-1989. Third, the detailed inclusion criteria are not given. The authors fail to discuss how large decreases in caries cast doubts on their analysis. For example, a decrease in DMFT of about five teeth within 15 years among 35-44 year olds. Surely such an unrealistically high decrease is a cause for reflection on the inclusion criteria and the use of a systematic review to assess trends.

This paper raises more questions than it answers. Should comparisons be made between studies with unequal sample sizes? How representative are the samples? How does the size of the decreases relate to possible risk factors? For example, is it feasible to get a decrease in prevalence of caries in 11-13 years of $30 \%$ in 10 years (Fig. 5 in the original article) without any organised interventions?

The authors state that their study 'has clearly shown' that the generally believed increase in caries in Africa is not supported. They should be more circumspect about their claims. The two of the five age groups assessed in which increases in DMFT were noted were the critical age groups, 11-15 years.

Aubrey Sheiham Dept of Epidemiology and Public Health University College, London, UK 